\title{
АНАЛІЗ РОБОТИ ОРНОГО АГРЕГАТУ 3 ТРАКТОРОМ МТЗ-80 ІЗ ДИФЕРЕНЦАЛЬНИМ І БЛОКОВАНИМ МІЖКОЛІСНИМ ПРИВОДОМ
}

\section{Рецензент - кандидат технічних наук В. В. Лоснко}

\begin{abstract}
Представлені результати експериментального дослідження роботи орного агрегату в складі трактора МТ3-80 та навісного плуга на супіщаному грунті з диференціальним та блокованим міжсколісним приводом заднього моста. В результаті аналізу отриманих нами експериментальних даних встановлено, щзо з блокованим приводом дотична сила тяги трактора зростає у межах від 3,99 до 21,5\% порівняно з диференціальним приводом. Зростання дотичної сили відбувається за рахунок збільшення обертаючого моменту на правому колесі, щзо знаходиться в борозні. Додаткова сила тяги використовується для переборення зростаючої сили опору руху агрегату. Блокований міжколісний привід призводить до погіршення керованості трактора та збільшення витрати палива в середньому на $12 \%$. Для підтримання прямолінійного руху агрегату необхідно тримати передні колеса трактора повернутими вправо; до того ж із блокованим приводом кут повороту коліс зростає.
\end{abstract}

Ключові слова: оранка, агрегат, трактор, диференціальний привід, блокований привід, обертаючий момент, сила тяги, витрата палива, коефіиієнт блокування, потужність, двигун, плуг, тягово-зчіпні показники.

Постановка проблеми. Універсально-просапні трактори класу 14 кН Мінського тракторного заводу обладнані системою блокування міжколісного диференціала заднього моста 3 гідравлічним приводом, що дає змогу вмикати блокований привід на тривалий час із метою покращання тягово-зчіпних показників трактора.

У процесі оранки грунтів агрегатом у складі трактора МТ3-80 і навісного плуга праві й ліві колеса трактора знаходяться у різних умовах зчеплення, а також відбувається перерозподіл його ваги внаслідок того, що праві колеса знаходяться у борозні, а ліві - на поверхні поля.

У зв'язку з цим викликає інтерес дослідження впливу блокованого приводу міжколісного диференціала на тягово-зчіпні якості, паливну економічність і керованість орного агрегату.
Аналіз останніх досліджень і публікацій, у яких започатковано розв'язання проблеми. Раніше [2] були проведені експериментальні дослідження стійкості прямолінійного руху трактора МТЗ-80 в умовах різного зчеплення коліс, коли одна сторона трактора рухалася по слизькій опорній поверхні (лід), а інша по поверхні з високим зчепленням (асфальт) із незначним навантаженням на гаку $(3,5-3,8$ кН). Такий режим роботи трактора характерний для транспортних робіт взимку.

У результаті досліджень нами встановлено, що із блокованим міжколісним приводом для забезпечення прямолінійного руху необхідно передні колеса трактора тримати повернутими на кут $5,16^{0}$, а 3 диференціальним приводом - на $2,18^{0}$. Кут повороту коліс збільшується зі зростанням швидкості трактора. Встановлено, що керованість трактора 3 блокованим приводом погіршується, а прохідність покрашується. Зростає також сила опору коченню.

Мета дослідження. Метою дослідження було встановлення впливу блокування міжколісного диференціалу заднього моста трактора МТЗ-80 та швидкості руху агрегату на його тягово-зчіпні показники. Трактор виконував оранку з навісним плугом на ділянці з супіщаним грунтом. Глибина оранки - 20-22 см. Експериментальні дослідження були проведенні згідно 3 договором із Мінським тракторним заводом [1].

Згідно із завданням, поставленим замовником досліджень, випробування орного агрегату проводилися в межах робочих швидкостей (4-10 км/год). Замірялися моменти на півосях ведучих коліс трактора, обертаючий момент двигуна та частота обертання колінчастого валу. В процесі аналізу результатів досліджень зроблена спроба оцінювання паливної економічності агрегату за різних режимів його роботи.

Матеріали і методи досліджень. Дослідження проводилися на передачах із другої по шосту. Для отримання необхідних даних трактор був обладнаний тензометричними датчиками, які 
1. Опосередковані значення результатів дослідження роботи орного агрегату

\begin{tabular}{|c|c|c|c|c|c|c|c|c|c|}
\hline Передача & $\mathrm{V}$, км/год & $\begin{array}{c}\text { Блоку- } \\
\text { вання }\end{array}$ & $\begin{array}{c}\mathrm{M}_{\text {кл, }} \\
\mathrm{KH} \bullet \mathrm{M}\end{array}$ & $\begin{array}{c}\mathrm{M}_{\mathrm{K \Pi}}, \\
\mathrm{\kappa} \cdot \mathrm{M}\end{array}$ & $\begin{array}{l}\sum \mathrm{M}_{\mathrm{K}}, \\
\mathrm{KH} \bullet \mathrm{M}\end{array}$ & $\begin{array}{l}\Delta \mathrm{M}_{\mathrm{K}}, \\
\mathrm{KH} \bullet \mathrm{M}\end{array}$ & $\mathrm{K}_{\mathrm{M}}$ & $\begin{array}{l}\mathrm{P}_{\mathrm{K}}, \\
\mathrm{\kappa H} \\
\end{array}$ & $\begin{array}{c}\mathrm{N}_{\text {д }} \\
\mathrm{\kappa BT}\end{array}$ \\
\hline \multirow{2}{*}{ II } & \multirow{2}{*}{3,58} & вИМКн. & 3,15 & 3,42 & 6,57 & 0,27 & 1,09 & 8,90 & 20,09 \\
\hline & & ввімкн. & 3,18 & 5,20 & 8,38 & 2,02 & 1,64 & 11,32 & 20,82 \\
\hline \multirow{2}{*}{ III } & \multirow{2}{*}{6,09} & вимкн. & 4,55 & 5,02 & 9,57 & 0,47 & 1,10 & 12,94 & 29,44 \\
\hline & & ввімкн. & 4,51 & 6,03 & 10,54 & 1,52 & 1,34 & 14,25 & 31,87 \\
\hline \multirow{2}{*}{ IV } & \multirow{2}{*}{7,48} & вимкн. & 4,93 & 5,69 & 10,62 & 0,76 & 1,15 & 14,36 & 38,42 \\
\hline & & ввімкн. & 4,24 & 7,59 & 11,83 & 3,35 & 1,79 & 15,99 & 41,58 \\
\hline \multirow{2}{*}{ V } & \multirow{2}{*}{8,85} & вимкн. & 4,74 & 5,22 & 9,96 & 0,48 & 1,10 & 13,46 & 43,42 \\
\hline & & ввімкн. & 5,02 & 7,49 & 12,51 & 2,47 & 1,49 & 16,90 & 51,81 \\
\hline \multirow{2}{*}{ VI } & \multirow{2}{*}{10,37} & ВИМКН. & 5,36 & 6,18 & 11,54 & 0,82 & 1,15 & 15,59 & 49,31 \\
\hline & & ввімКн. & 4,84 & 7,18 & 12,02 & 2,34 & 1,48 & 16,24 & 41,95 \\
\hline
\end{tabular}

давали можливість заміряти значення обертаючих моментів на півосях заднього моста, обертаючого моменту на колінчастому валу двигуна, частоти обертання колінчастого валу, швидкості руху агрегату. Параметри досліджень записувалися на осцилограми з використанням мобільної тензометричної станції на базі автомобіля ГАЗ53А. Коефіцієнт блокування та сила тяги трактора обчислювались аналітично.

Результати досліджень. Результати досліджень, отримані після обробки осцилограм, представлені в таблиці 1.

Сумарний обертаючий момент $\sum \mathrm{M}_{\mathrm{K}}$ визначався за формулою: $\Sigma \mathrm{M}_{\mathrm{K}}=\mathrm{M}_{\kappa л}+M_{\kappa n}$,

де: $\mathrm{M}_{\text {кл }}$ - обертаючий момент на лівій півосі; $\mathrm{M}_{\mathrm{kn}}$ - обертаючий момент на правій півосі.
Різниця обертаючих моментів визначалася за формулою:

$$
\Delta M_{\kappa}=M_{\kappa n}-M_{\kappa n} \text {. }
$$

Коефіцієнт нерівномірності розподілу обертаючих моментів між півосями $\mathrm{K}_{\mathrm{m}}$ визначався за формулою:

$$
K_{M}=\frac{M_{\kappa n}}{M_{\kappa r}} .
$$

Дотична сила тяги трактора $\mathrm{P}_{\mathrm{\kappa}}$ визначалася за формулою:

$$
P_{\kappa}=\frac{\Sigma M_{\kappa}}{R}
$$

де $R=0,74$ м - радіус ведучих коліс.

Потужність двигуна $\mathrm{N}_{д}$ взята 3 [1].

$$
\mathrm{P}_{\mathrm{K}}, \mathrm{KH}
$$

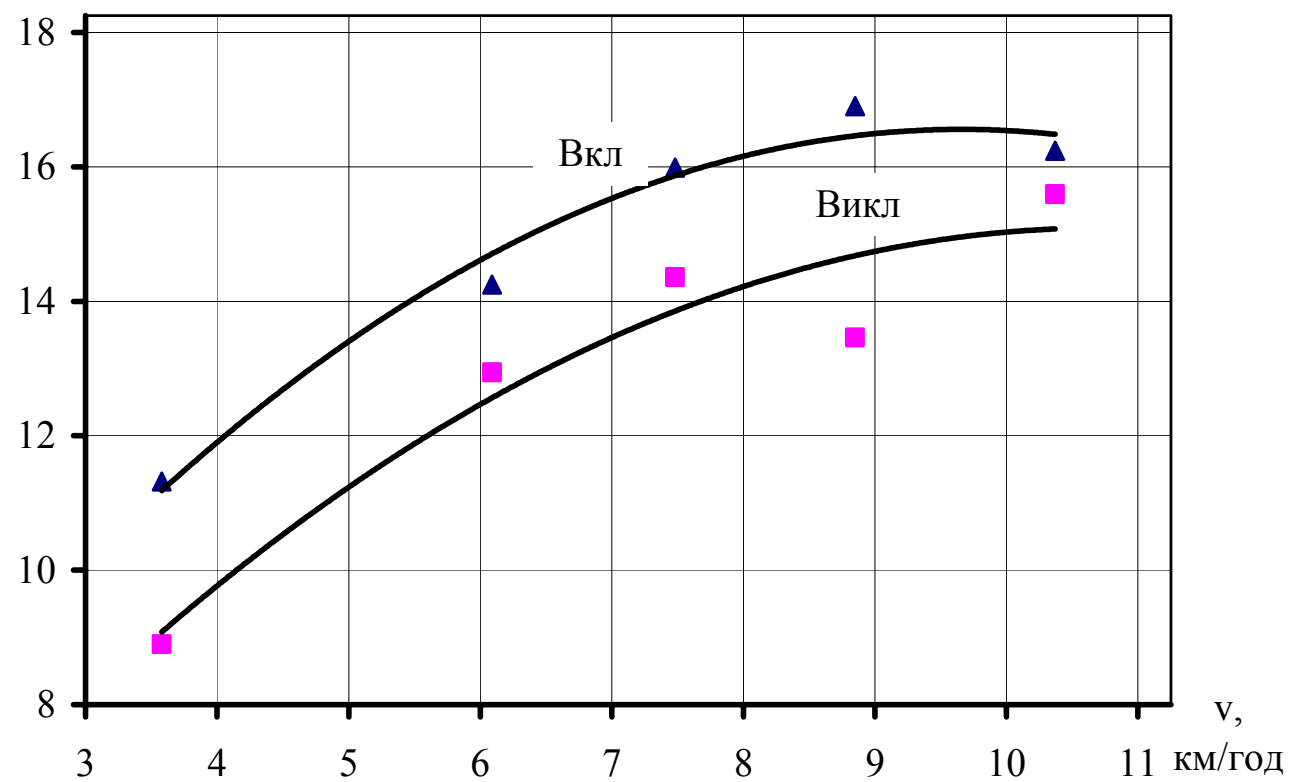

Рис. 1. Залежність дотичної сили тяги трактора від ивидкості руху 


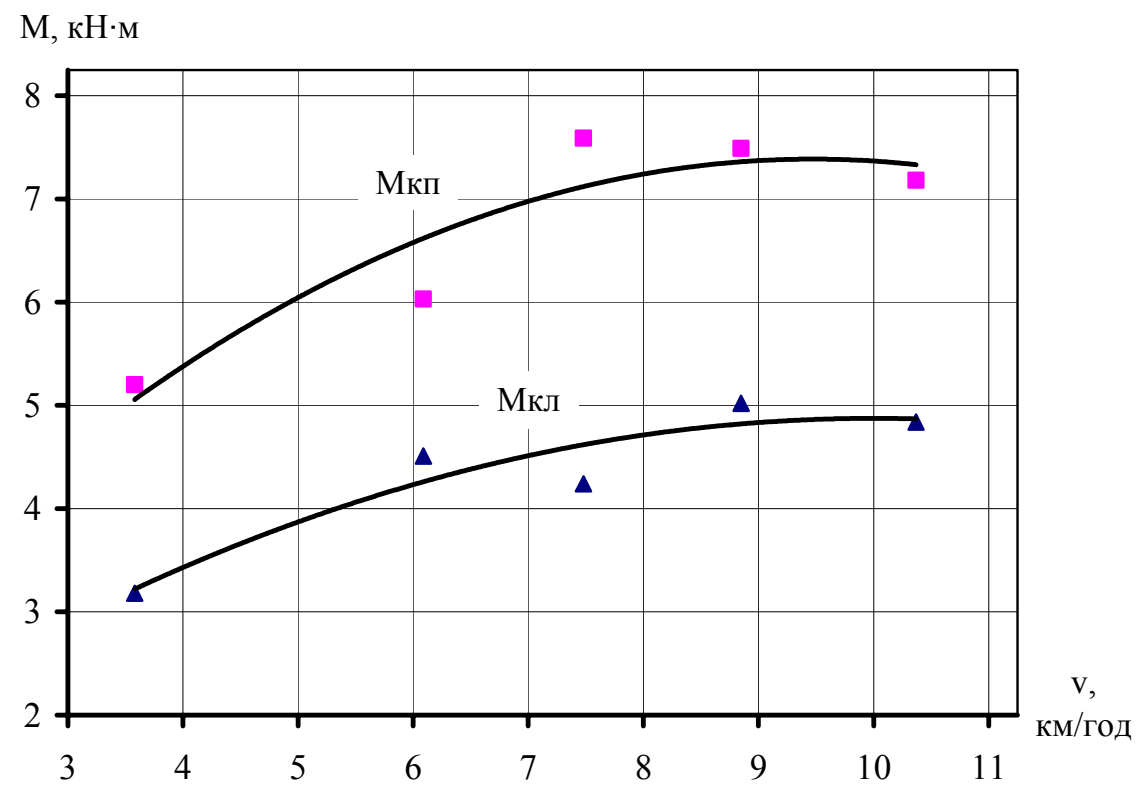

\section{Рис. 2. Залежність обертаючих моментів на півосях від ивидкості руху трактора з блокованим міжколісним приводом}

Аналіз результатів дослідження (табл. 1) дає підстави зробити висновки, що блокування диференціала заднього моста призводить до збільшення сумарного ведучого моменту $\sum \mathrm{M}_{\mathrm{K}}$ (а отже, і сили тяги $\mathrm{P}_{\mathrm{k}}$ ). Це видно також із графіків, представлених на рисунку 1.

В основному це досягається за рахунок зростання моменту на правому $\mathrm{M}_{\text {кп }}$ колесі, яке знаходиться в борозні, тому що на нього перерозподіляється вага трактора внаслідок його поперечного нахилу, що видно з рисунка 2.

Більше значення моменту на правому колесі спостерігалося навіть із вимкненим блокуванням диференціала за тієї ж причини, але коефіцієнт нерівномірності розподілу моментів $K_{м}$ був значно менший, ніж із блокованим приводом коліс. Так, за даними досліджень (табл. 1), нерівномірність розподілу моментів із вимкненим блокуванням за рахунок блокуючої дії сил тертя в диференціалі досягала $\Delta \mathrm{M}_{\mathrm{K}}=0,27-0,82 \mathrm{\kappa H} \cdot \mathrm{M}$ (7-9 \% від сумарного моменту). При цьому середне значення коефіцієнта нерівномірності розподілу моментів $\mathrm{K}_{\mathrm{M}}$ знаходилося в межах $\mathrm{K}_{\mathrm{M}}=1,09-1,15$. Значення коефіцієнта $\mathrm{K}_{\mathrm{m}}$ має тенденцію до зростання зі збільшенням швидкості агрегату.

У разі оранки з ввімкненою системою блокування диференціала перерозподілена частина моменту на ведучих колесах становила 15,5$33,0 \%$ від сумарного $\left(\Delta \mathrm{M}_{\mathrm{K}}=1,52-3,35 \mathrm{\kappa H} \bullet \mathrm{M}\right)$, що відповідає значенням коефіцієнта нерівномірності розподілу моменту $\mathrm{K}_{\mathrm{M}}=1,34-1,79$.

Робота із ввімкненим блокуванням, за даними дослідження, призводила до збільшення сумар- ного ведучого моменту від 3,99 до 21,5 \% у порівнянні 3 оранкою в тих же умовах із вимкненим блокуванням. Відповідно зростає й сила тяги трактора $\mathrm{P}_{\kappa}$ (рис. 1). Додаткова сила тяги при блокованому приводі використовувалася для переборення сили опору коченню трактора, тому що для підтримання його прямолінійного руху необхідно було повертати передні керовані колеса вправо на більший кут, аніж із диференціальним приводом, у зв'язку з необхідністю переборення відхиляючого моменту, викликаного різними моментами на півосях. Отже, робота 3 блокованим міжколісним приводом погіршує керованість трактора у процесі оранки.

Спостерігалося зростання тягового опору плуга при збільшенні швидкості руху агрегату в межах $43,1 \%$ із диференціальним приводом i $33,0 \%$ - із блокованим.

Слід враховувати, що робота на другій і шостій передачах за швидкістю руху не відповідає агротехнічним вимогам до оранки.

Потужність двигуна $\mathrm{N}_{\text {д }}$ за даними досліджень, у найбільшій мірі (88 \% від номінальної) використовувалася на п'ятій передачі з блокованим приводом (табл. 1). На шостій передачі оберти двигуна зменшувалися внаслідок перевантаження - і він не розвивав повної потужності.

Отримані дані досліджень свідчать про незначний позитивний вплив блокування диференціалу на тягово-зчіпні якості трактора МТ3-80 у процесі оранки слабо зв'язаних піщаних грунтів.

Була зроблена спроба аналізу паливної економічності трактора на оранці з диференціальним i 


\section{2. Результати розрахунків витрати палива}

\begin{tabular}{|c|c|c|c|c|c|c|c|}
\hline Передача & $\mathrm{V}$, км/год & $\begin{array}{c}\text { Блоку- } \\
\text { вання }\end{array}$ & $\mathrm{M}_{\text {Д }}, \mathrm{H} \cdot \mathrm{M}$ & $\begin{array}{l}\mathrm{n}_{\mathrm{d},}, \\
\mathrm{XB}^{-1}\end{array}$ & $\mathrm{~N}_{\mathrm{d}}, \mathrm{\kappa BT}$ & $\begin{array}{c}\mathrm{g}_{\mathrm{e}}, \\
\text { г/кВт·год }\end{array}$ & $\begin{array}{c}\mathrm{G}_{\mathrm{t}}, \\
\text { кг/год }\end{array}$ \\
\hline \multirow{2}{*}{ II } & \multirow{2}{*}{3,58} & вимкн. & 76,02 & 2524,1 & 20,09 & - & - \\
\hline & & ввімкн. & 86,33 & 2303,2 & 20,82 & 367,2 & 7,64 \\
\hline \multirow{2}{*}{ III } & \multirow{2}{*}{6,09} & вимкн. & 123,61 & 2274,5 & 29,44 & 292,4 & 8,61 \\
\hline & & ввімкн. & 133,42 & 2281,2 & 31,87 & 300,0 & 9,56 \\
\hline \multirow{2}{*}{ IV } & \multirow{2}{*}{7,48} & вимкн. & 163,83 & 2239,6 & 38,42 & 262,5 & 10,09 \\
\hline & & ввімкн. & 175,6 & 2261,3 & 41,58 & 265,2 & 11,03 \\
\hline \multirow{2}{*}{ V } & \multirow{2}{*}{8,85} & вимкн. & 191,30 & 2167,6 & 43,42 & 254,3 & 11,04 \\
\hline & & ввімкн. & 230,53 & 2146,3 & 51,81 & 250,0 & 12,76 \\
\hline \multirow{2}{*}{ VI } & \multirow{2}{*}{10,37} & вимКн. & 245,25 & 1920,1 & 49,31 & 246,2 & 12,14 \\
\hline & & ввімкн. & 234,46 & 1708,7 & 41,95 & 250,0 & 10,49 \\
\hline
\end{tabular}

блокованим приводом. Для цього визначались оберти колінчастого вала двигуна $\mathrm{n}_{\mathrm{d}}$ за формулою:

$$
n_{d}=9554 \cdot \frac{N_{d}}{M_{d}} .
$$

Питома витрата палива $\mathrm{g}_{\mathrm{e}}$ залежно від обертів колінвалу визначалася з регуляторної характеристики двигуна [3].

Витрата палива за годину $\mathrm{G}_{\mathrm{T}}$ визначалася за формулою:

$$
G_{t}=\frac{g_{e} \cdot N_{d}}{1000} .
$$

Результати розрахунків витрати палива представлені в таблиці 2.

Аналіз даних таблиці 2 дає підстави зробити висновки, що $з$ блокованим міжколісним приводом заднього моста годинна витрата палива збільшується в порівнянні $з$ диференціальним приводом на 9-16 \% (у середньому на $12 \%$ ).

\section{БІБЛІОГРАФІЯ}

1. Исследование управляемости и нагруженности силовой передачи трактора кл. 1,4 тс с автоблокирующимся дифференциалом: Отчет о НИР / Полтавский сельхозинститут. - МТЗ. - №617. Полтава, 1974. - 32 с.

2. Лихвенко С. П., Харак Р. М. Експериментальне дослідження стійкості прямолінійного руху трак-

\section{Висновки:}

1. Із блокованим міжколісним приводом заднього моста трактора МТЗ-80 зростає дотична сила тяги $\mathrm{P}_{\text {к }}$ у межах від 3,99 до 21,5 \% порівняно $з$ диференціальним приводом. Додаткова сила тяги використовується для переборення зростаючої сили опору руху трактора.

2. Зростання дотичної сили тяги відбувається, в основному, за рахунок збільшення обертаючого моменту на правому колесі, що знаходиться в борозні.

3. Для підтримання прямолінійного руху орного агрегату необхідно тримати передні керовані колеса трактора повернутими вправо.

4. Зі збільшенням швидкості агрегату тяговий опір плуга суттєво зростає як за диференціального, так і блокованого приводу.

5. Блокований міжколісний привід призводить до погіршення керованості трактора та збільшення витрати палива в середньому на $12 \%$.

тора в умовах різного зчеплення ведучих коліс // Вісник Полтавської державної аграрної академiï. - 2012. - № 1. - С. 178-180.

3. Тяговые характеристики сельскохозяйственных тракторов. Альбом-справочник. - М. : Россельхозиздат, 1979. $-240 \mathrm{c}$. 